\title{
Telomerase activity in human gynaecological malignancies
}

\author{
H Gorham, K Yoshida, T Sugino, G Marsh, S Manek, M Charnock, D Tarin, S Goodison
}

\begin{abstract}
Aim-To evaluate whether increased telomerase activity can be clinically useful for detecting malignant cells in a variety of gynaecological specimens.

Methods-Telomerase activity was examined in frozen tissue samples of histologically confirmed lesions of the endometrium, ovary, and cervix. It was also assessed in exfoliated cells in cervical smears from patients with premalignant and malignant lesions and in ascitic fluid obtained from cases with malignant or non-malignant ovarian tumours.

Results-Solid tissues from carcinomas were telomerase positive in all specimens of endometrial (6/6) and cervical (6/6) origin, and in almost all from the ovary (12/13). Normal tissues from the cervix $(0 / 5)$ and the ovary (0/5) were telomerase negative, but samples from normal endometrium were found to show telomerase activity, possibly due to the cyclical regenerative nature of this tissue. Conversely, dissociated cells in cervical smears from preneoplastic and frankly neoplastic lesions rarely showed detectable telomerase activity. Thus smears from patients with malignant tumours were only positive in one of two patients, whereas those from CIN-2 (0/5) and CIN-3 (1/17) lesions and from normal (0/10) samples were almost all negative. Telomerase activity was also scarcely detectable in cells obtained from ascitic fluid from patients with ovarian tumours.

Conclusions-As in many other organs, telomerase activity is increased in solid tissue specimens from malignant tumours of the female reproductive tract, but it is not yet a reliable indicator of the presence of exfoliated cancerous or precancerous cells in clinical specimens from such lesions. Interpretation should be guarded until more extensive studies have been conducted. The data on solid tissues presented here confirm that activation of this enzyme is a major hallmark of the neoplastic process.

(F Clin Pathol 1997;50:501-504)
\end{abstract}

Keywords: telomerase activity; gynaecological carcinoma; early diagnosis

Telomeres are specialised nucleoprotein structures at the ends of eukaryotic chromosomes in which the DNA is composed of several hundred repeats of a simple hexanucleotide sequence (TTAGGG) extending up to $30 \mathrm{~kb}$. These telomeric regions play an important role in the structural integrity and function of chromosomes because they anchor the terminal regions to the nuclear membrane and protect them from untimely recombination events. The telomeres are believed to act as a buffer zone which allows for the loss of terminal DNA that occurs each time a chromosome is replicated without disruption of vital protein coding sequences. Replication related shortening of telomeric DNA to a critical length has been implicated as a signal for cells to stop dividing and to enter a senescent state. As a result of this "end-replication" problem, somatic cells have a limited proliferative capacity. Maintenance of telomere length is therefore considered to be necessary for continued cell division and immortalisation. ${ }^{1-4}$ This can be achieved in vivo by the activation of telomerase, a ribonucleoprotein RNA dependent DNA polymerase that adds telomeric hexanucleotide repeats to the ends of replicating chromosomes. ${ }^{56}$

Recent investigations have shown that telomerase activity is demonstrable in the vast majority of human cancer cell lines and tumours tested, but it is absent or present at very low levels in somatic cells. ${ }^{78}$ The "telomeric repeat amplification protocol" (TRAP assay) is extremely sensitive and has been used to detect the presence of telomerase activity in carcinomas from a number of organs including

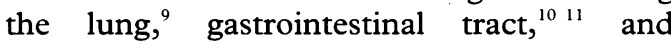
bladder. ${ }^{12}$ However, to date few studies have been undertaken to assess the value of the TRAP assay in the detection of carcinoma in samples from the female reproductive tract (endometrium, ovary, and cervix).

\section{Methods}

TISSUE SPECIMENS

Tissue specimens were collected from six endometrial carcinomas, eight normal endometria, 13 ovarian carcinomas, five benign ovarian tumours, six cervical carcinomas, and five normal cervices. These were immediately snap frozen and stored in liquid nitrogen until use. Cryostat sections were examined to confirm the histological identity of all tissue samples before analysis.

Ascites fluid from eight patients with ovarian carcinomas and from four without carcinomas was centrifuged to collect suspended cells. Cytological preparations were examined and the remainder of the cell pellet snap frozen in liquid nitrogen before storage at $-70^{\circ} \mathrm{C}$. 


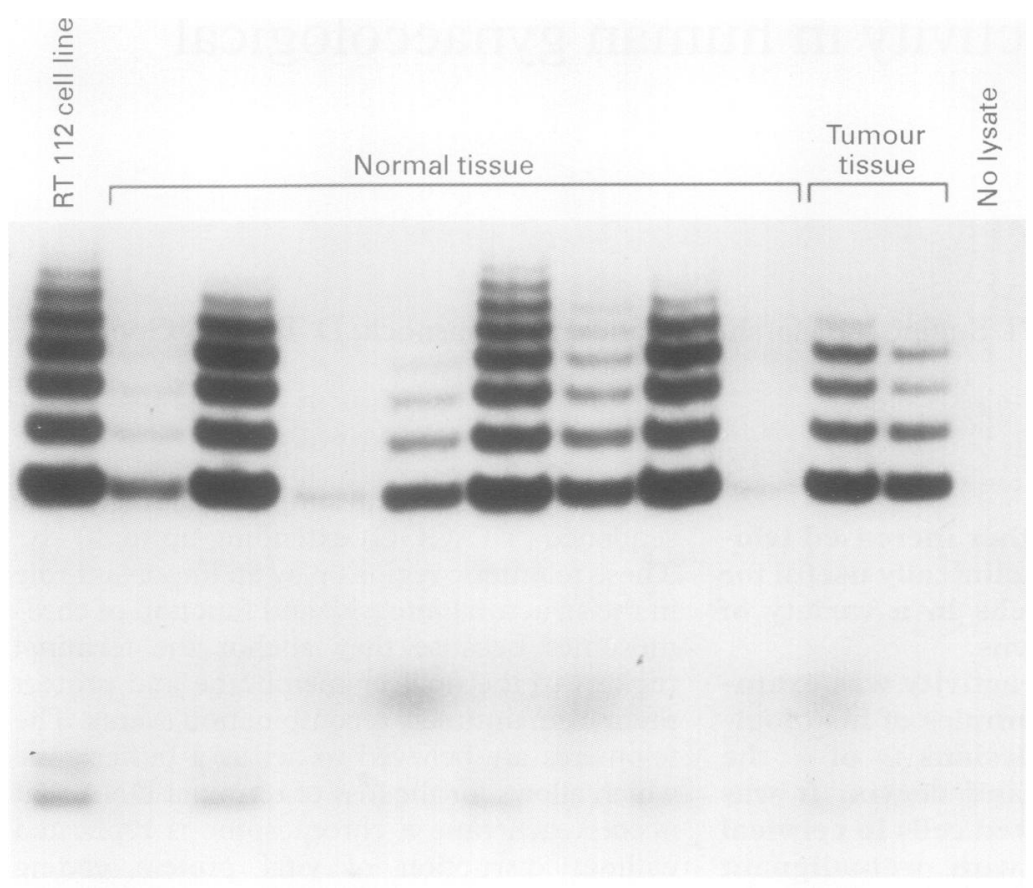

Figure 1 Telomerase activity in normal and malignant endometrium: $6 \mu \mathrm{g}$ of protein from tissue lysates were used for each reaction; 6 base pair ladders could clearly be seen in normal as well as tumour tissues. The RT112 human carcinoma cell line was used as a positive control. Telomerase activity was not detected in lysates pretreated with RNase $A$. No telomerase activity was detected in a reaction mixture containing no tissue lysate.

Cervical smears were obtained with informed consent from five patients with cervical intraepithelial neoplasia (CIN) II, 17 with CIN III, two with carcinomas (one microinvasive, one invasive), and 10 with no detectable lesion. The samples used consisted of the redundant cellular material on the spatulae after preparation of cytological smears for diagnostic purposes. The cells were resuspended in phosphate buffered saline, centrifuged, and stored as above.

PROTEIN EXTRACTION AND TELOMERASE ASSAYS Protein extractions were performed according to protocols published previously. ${ }^{8}$ Briefly, cell pellets or 20 cryostat sections $10 \mu \mathrm{m}$ thick from tissue samples were resuspended in TRAP lysis buffer, incubated on ice, and centrifuged. The resulting supernatant was snap frozen in liquid nitrogen and stored at $-70^{\circ} \mathrm{C}$. Six micrograms of protein extract were used for each telomerase assay. Telomerase activity was detected by the TRAP assay. ${ }^{8}$ This detects the presence of telomerase activity by its ability to extend a synthetic oligonucleotide substrate which is added to the reaction mixture. The enzyme can act processively, so many extended DNA molecules of different lengths are produced. These are then amplified by polymerase chain reaction (PCR) using specific primers and the products are visualised as a ladder pattern of bands at six base pair intervals. RNase sensitivity of the TRAP assay was assessed by digesting $10 \mu \mathrm{l}$ of the cell extract (10 $\mu \mathrm{g}$ protein) with $0.5 \mu \mathrm{g}$ of RNase A (Boehringer Mannheim, Germany) for 20 minutes at $37^{\circ} \mathrm{C}$, and $6 \mu \mathrm{g}$ of the protein extract were used in the TRAP assay. To reveal the possible presence of PCR inhibitors, extracts were further diluted to $0.6 \mu \mathrm{g}$ of protein per assay.
Table 1 Telomerase activity in normal and malignant tissues

\begin{tabular}{lcl}
\hline Sample & $\begin{array}{l}\text { No of } \\
\text { cases }\end{array}$ & $\begin{array}{l}\text { No of positive } \\
\text { cases }\end{array}$ \\
\hline Solid tissue & & \\
$\quad$ Endometrium carcinoma & 6 & $6 / 6$ \\
$\quad$ Endometrium normal & 8 & $5 / 8$ \\
Ovarian carcinoma & 13 & $12 / 13$ \\
Ovarian non-malignant & 5 & $0 / 5$ \\
Cervix carcinoma & 6 & $6 / 6$ \\
$\quad$ Cervix normal & 5 & $0 / 5$ \\
Fluids and smears & & \\
Ovarian ascites carcinoma & 8 & $2 / 8$ \\
Ovarian ascites non-malignant & 4 & $0 / 4$ \\
Cervical smear carcinoma & 2 & $1 / 2$ \\
$\quad$ (CIN III) & 17 & $1 / 17$ \\
$\quad$ (CIN II) & 5 & $0 / 5$ \\
$\quad$ Normal & 10 & $0 / 10$ \\
\hline
\end{tabular}

$\mathrm{CIN}$, cervical intraepithelial neoplasia.

\section{Results}

\section{ENDOMETRIUM}

Telomerase activity, detected by the presence of the characteristic 6 base pair ladder, was observed in samples of both normal and carcinomatous endometrium (fig 1, table 1). The signals from these tissue samples were very intense. Of the six carcinoma cases, all were positive, but clearly positive results were also seen in five of the eight samples of normal endometrium. In addition, a weak signal was seen in one of the remainder. Histologically there was no evidence of accumulation of inflammatory cells in any of the samples assayed.

\section{OVARIAN TISSUE AND ASCITIC FLUIDS}

Telomerase activity was detected in $12 / 13$ carcinomas and $0 / 5$ non-malignant ovarian tissue samples (fig 2, table 1). As it could only be detected in samples of carcinoma tissue and not in non-malignant tissue, enzyme activity was next assayed in the cells suspended in malignant and non-malignant ascitic fluid from patients with ovarian lesions. Of the eight ascitic fluids from patients with cytologically confirmed malignant tumours, only two gave a clearly positive result (fig $2 \mathrm{~A}$ ). All the remaining samples showed low level telomerase activity relative to the telomerase negative nonmalignant group, but these weakly positive samples contained blood cells and lymphocytes, reported to possess telomerase activity. ${ }^{13}$ We were able to obtain four solid tissue samples from cases used in the ascites study (fig 2B). Case 1 was tissue obtained from a benign tumour and showed no telomerase activity, agreeing with the ascites data (fig 2A). Case 5 was tissue obtained from a patient undergoing chemotherapy and very weak telomerase activity was obtained both from the tissue and from the ascites. Cases 9 and 10 were malignant tumours and tissue samples from both gave good positive results, as expected. However, of the corresponding ascites samples, only that from case 9 gave a clearly positive result (fig 2A) despite the cytological confirmation of many exfoliated malignant cells in case 10. To assess whether such results were attributable to artefactual interference with the assay by inhibitory factors, all the negative samples were diluted 10 -fold and 100 -fold, but no telomerase activity was revealed. 
CERVICAL TISSUE AND CERVICAL SMEARS

Telomerase activity in cervical tissue appeared to be present only in carcinoma samples (6/6), with no detectable activity in normal tissue $(0 / 5)$ (table 1). As in ascitic fluids, the visual detection of carcinoma cells in cervical smears can be difficult and time consuming. We therefore evaluated the telomerase assay on cervical smear samples collected from patients cytologically diagnosed as having CIN II, CIN III, or cervical carcinomas. Telomerase activity could not be detected in cells from any of five CIN II smears and in only one of 17 CIN III smears. No tumour could be seen in routinely stained histology sections of the cone biopsy from the patient with the single CIN III smear that appeared to be telomerase positive. However, of the two confirmed cervical carcinoma smears, the invasive carcinoma gave a clearly positive result, but the microinvasive carcinoma was negative.

\section{Discussion}

It is widely reported that telomerase activity is only significantly present in germ line cells and immortal cancer cells. However, it has also been detected in some normal adult tissues and cell populations. Thus for example it has recently been reported that low levels of telomerase activity are present in human lymphocytes and haematopoietic progenitor cells. ${ }^{13-15}$ It has been suggested that the levels of telomerase activity may correlate with the proliferative status of the stem cells within these cell lineages. Furthermore, activity of this enzyme has been observed in intestine ${ }^{16}$ and in normal human skin, ${ }^{17} 18$ particularly in hair follicles, ${ }^{19}$ where actively replicating stem cells are known to reside at certain stages in the cycle of hair production. The endometrium also undergoes cyclical proliferation and differentiation during the menstrual cycle and it is inferred that the stem cells resident in the normal decidua basalis are responsible for the telomerase activity detectable in this tissue. It can therefore be concluded that telomerase activity is not a particularly useful indicator of the presence of tumour cells within the endometrium, because of the high levels of activity of this enzyme in normal tissue. Even so, detailed study of telomerase activity in proliferative and secretory phase endometrium and in postmenopausal tissue could give insights into the physiological regulation of this enzyme.

Enzyme activity correlated well with the presence of cancer in solid cervical tissue specimens and was not detectable in normal controls, but it was seen in only one of 22 smears from premalignant CIN II and CIN III lesions. Hence it would appear to be of limited practical value for the detection of early non-invasive lesions, but further studies on cervical epithelia from the transition zone could be valuable for the identification of the precise stage at which telomerase is activated during the multistage development of cancers. Telomerase activity has been detected in exfoliated cells in urine from a significant proportion of bladder cancer patients, ${ }^{12}$ in washings from colectomy specimens containing carcinomas, ${ }^{20}$ and in fine needle aspirates of breast carcinomas. ${ }^{21}$ Therefore, as the assay is sensitive enough to detect small numbers of cancer cells, it may be that the preneoplastic epithelial cells in CIN lesions have not yet reached the threshold of chromosomal instability at which increased telomerase activity is triggered.

As in the case of cervical cancer, fresh tissue specimens of ovarian cancer all showed strong telomerase activity, but it was not detectable in any of our samples of non-neoplastic ovarian tissue. In the investigation of patients with suspected ovarian carcinomas it would be of great practical advantage to be able to establish a

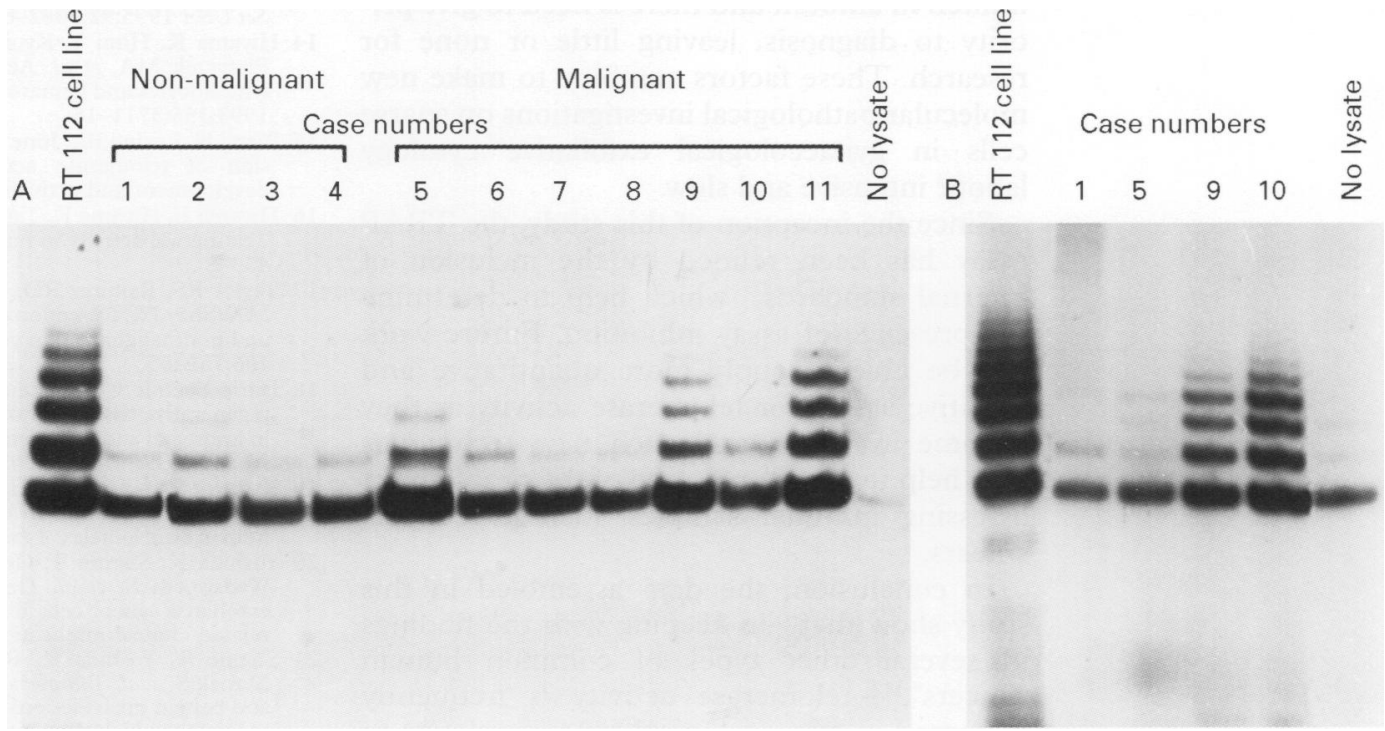

Figure 2 (A) Telomerase activity in ascites from patients with non-malignant (cases 1-4) and malignant (cases 5-11) ovarian tumours: $6 \mu \mathrm{g}$ of cell extract protein was used for each reaction. Only two malignant cases (Nos 9 and 11) gave clearly positive results. The remaining cases, whether non-malignant or malignant, gave a negative/weak six base pair ladder when compared to the no lysate control. Telomerase activity was not detected in lysates pretreated with RNase A. The RT112 human carcinoma cell line was used as a positive control. (B) Telomerase activity in ovarian tissues from patients with matched ascites samples. The same case numbers apply for the tissue and ascites specimens from the given patient; $6 \mu$ of tissue extract protein was used in each reaction. Telomerase activity was not detected in lysates pretreated with $R N a$ ase $A$. The RT112 tumour cell line was used as a positive control.
The 
diagnosis by examination of ascitic or cyst fluid obtained by the minimally invasive procedure of paracentesis. However, our analysis of ascitic fluids did not show a good correlation between the presence of tumour cells and increased telomerase activity. Dilution studies have previously shown the presence of Taq polymerase inhibitors in telomerase negative tumour extracts, ${ }^{522}$ but using similar analyses we did not find evidence of inhibitors in cells collected from the ascitic fluids in our study. This suggests that any activity associated with exfoliated neoplastic cells in the ascites is masked by the overwhelming background of nonneoplastic mesothelial and other cells shed into the fluid. Dilution of the telomerase protein from cancer cells by other proteins from the non-neoplastic cell population could cause such an effect.

Our data on tissue samples from gynaecological malignancies adds to the growing evidence that telomerase is an important cancer specific marker that is expressed in the majority of cancers. However, although present methods can detect the presence of telomerase activity in even a single isolated cancer cell, we did not find the assay to be capable of detecting a subpopulation of exfoliated cancer cells among the abundant mesothelial and inflammatory cells in clinical samples.

The information obtained in this initial study therefore appears to limit the practical value of this assay method for the non-invasive early detection of gynaecological malignancy by examination of exfoliated cells, but for definitive conclusions much larger studies will be needed. There are substantial practical difficulties in conducting such work, because in prospective studies one has to examine about five to 10 times as many non-malignant samples of cervical smears and ascites samples as malignant or premalignant ones. Furthermore, smears and ascites samples are often very limited in amount and there is need to give priority to diagnosis, leaving little or none for research. These factors combine to make new molecular pathological investigations on sparse cells in gynaecological exfoliative cytology labour intensive and slow.

Since the inception of this study, the TRAP assay has been refined by the inclusion of internal standards ${ }^{23}$ which help to determine the presence of assay inhibition. Future work will be able to apply more quantitative and sensitive assays for telomerase activity as they become available, and such new techniques may help to overcome some of the problems of assessing minimal samples such as cervical smears.

In conclusion, the data assembled in this study show that -in keeping with the findings in several other types of common human cancers $^{9-12}$ - telomerase activity is frequently increased in gynaecological cancers relative to corresponding normal tissue. Investigations on exfoliated cells from such tumours have not yet yielded a practical method to supplement or improve upon the current labour intensive microscopical method, for early detection. However, the results on telomerase activity in small solid tissue specimens documented here give cause for optimism and indicate that the difficulties can be overcome. Thus our findings indicate that further exploration of increased telomerase activity in gynaecological cancer is an important priority for understanding the mechanisms involved in neoplasia, and for the clinical application of such advances.

We would thank all members of staff of the colposcopy unit at the John Radcliffe Hospital for the collection of gynaecological samples, Heather Dorricott and Helene Mellor for technical assistance, and Linda Summerville for help in preparation of the manuscript.

1 Shay JW, Werbin H, Wright WE. You haven't heard the end of it: telomere loss may link human aging with cancer. Can Aging 1995;14:51 1-24.

2 Harley CB. Telomere loss: mitotic clock or genetic time bomb? Mutat Res 1991;256:271-82.

3 Counter CM, Avilion AA, LeFeuvre CE, Atewart NG, Greider CW, Harley CB, et al. Telomere shortening associated with chromosome instability is arrested in immortal cells which express telomerase activity. EMBO ₹ 1992;11: 1921-9.

4 Greider CW. Mammalian telomere dynamics: healing, fragmentation, shortening and stabilization. Curr Opin Genetics Dev 1994;4:203-11.

5 Morin GB. The human telomere terminal transferase enzyme is a ribonucleoprotein that synthesizes TTAGGG repeats. Cell 1989;59:521-9.

6 Greider CW, Blackburn EH. The telomere terminal transferase of Tetrahymena is a ribonucleoprotein enzyme with two kinds of primer specificity. Cell 1987;51:887-98.

7 Counter CM, Hirte HW, Bacchetti S, Harley CB. Telomerase activity in human ovarian carcinoma. Proc Natl Acad Sci USA 1994;91:2900-4.

8 Kim NW, Piatyszek MA, Prowse KR, Harley CB, West MD, Ho PLC, et al. Specific association of human telomerase Ho PLC, et al. Specific association of human telomerase activity

9 Hiyama K, Hiyama E, Ishioka S, Yamakido M, Inai K, Gazdar AF, et al. Telomerase activity in small-cell and nonsmall-cell lung cancers. F Natl Cancer Inst 1995;87:895902

10 Hiyama E, Yokoyama T, Tatsumoto N, Hiyama K, Imamura Y, Murakami Y, et al. Telomerase activity in gastric cancer. Cancer Res 1995;55:3258-62.

11 Tahara $H$, Kuniyasu H, Yokozaki H, Yasui W, Shay JW, Toshinori I, et al. Telomerase activity in preneoplastic and neoplastic gastric and colorectal lesions. Clin Cancer Res 1995;1:1245-51.

12 Yoshida K, Sugino T, Tahara H, Woodman A, Bolodeoku J, Nargund V, et al. Telomerase activity in bladder carcinoma and its implication for non-invasive diagnosis by detection of exfoliated cancer cells in urine. Cancer 1997;79:362-9.

13 Broccoli D, Young JW, de Lange T. Telomerase activity in normal and malignant hematopoietic cells. Proc Natl Acad Sci USA 1995;92:9082-6.

14 Hiyama K, Hirai Y, Kyoizumi S, Akiyama M, Hiyama E, Piatyszek MA, et al. Activation of telomerase in human lymphocytes and hematopoietic progenitor cells. F Immunol 1995;155:3711-15.

15 Weng N, Levine BL, June CH, Hodes RJ. Regulated expression of telomerase activity in human $T$ lymphocyte development and activation $f$ Exp Med 1996;183:2471-9.

16 Hiyama E, Hiyama K, Tatsumoto N, Shay JW, Yokoyama T. Telomerase activity in human intestine. Int $\mathcal{F}$ Oncol 1996;9: 453-8.

17 Taylor RS, Ramirez RD, Ogoshi M, Chaffins M, Piatyszek MA, Shay JW. Detection of telomerase activity in malignant and nonmalignant skin conditions. $\mathcal{F}$ Invest Dermatol 1996 106:759-65.

18 Harle-Bachor C, Boukamp P. Telomerase activity in the regenerative basal layer of the epidermis in human skin and in immortal and carcinoma-derived skin keratinocytes. Proc in immortal and carcinoma-derived stin

19 Ramirez RD, Wright WE, Shay JW, Taylor RS. Telomerase activity concentrates in the mitotically active segments of activity concentrates in the mitotically active segments

20 Yoshida K, Sugino T, Goodison S, Warren BF, Nolan D, Wadsworth $\mathrm{S}$, et al. Detection of telomerase activity in exfoliated cancer cells in colonic luminal washings and its related clinical implications. Br f Cancer 1997;75:548-53.

21 Sugino T, Yoshida K, Bolodeoku J, Tahara H, Buley I, Manek S, et al. Telomerase activity in human breast cancer and benign breast lesions: diagnostic applications in clinical specimens, including fine needle aspirates. Int $\mathcal{f}$ Cancer (Pred Oncol) 1996;69:301-6.

22 Piatyszek MA, Kim NW, Weinrich SL, Hiyama K, Hiyama $\mathrm{E}, \mathrm{Wright}$ WE, et al. Detection of telomerase activity in human cells and tumors by a telomeric repeat amplification protocol (TRAP). Method Cell Sci 1995;17:1-15.

23 Wright WE, Shay JW, Piatyszek MA. Modifications of a telomeric repeat amplification protocol (TRAP) result in telomeric repeat amplification protocol (TRAP) result in increased reliability, 